\title{
Genetic Allee effects on performance, plasticity and developmental stability in a clonal plant
}

\author{
Markus Fischer, Mark van \\ Kleunen and Bernhard Schmid \\ Institut für \\ Umweltwissenschaften, \\ Universität Zürich \\ Winterthurerstr. 190, $\mathrm{CH}-8057$ \\ Zürich, Switzerland \\ E-mail: \\ fischerm@uwinst.unizh.ch
}

\begin{abstract}
Negative effects of small population size on fitness, so-called Allee effects, may threaten population persistence even in intact habitat remnants. We studied genotypes of 14 isolated populations of the clonal plant Ranunculus reptans, for which molecular genetic (RAPD-) variability is higher for large than for small populations. In a competition-free greenhouse environment vegetative offspring of genotypes from large populations produced more rosettes and flowers, indicating higher fitness. Within-genotype coefficients of variation in performance traits, indicating developmental instability, were lower for genotypes from populations with higher RAPDvariability. In competition with a taller grass, we found relative reduction in leaf length less pronounced for plants from large populations, suggesting higher adaptive plasticity. Our experimental study of a plant with predominantly vegetative reproduction suggests, that negative genetic effects of recent habitat fragmentation, which so far rather were expected in plants with frequent sexual reproduction, are more severe and more common than previously acknowledged.
\end{abstract}

\section{Keywords}

Adaptive phenotypic plasticity, Allee effect, clonal plant, conservation, developmental instability, genetic erosion, population size, rare plant, vegetative reproduction.

\section{INTRODUCTION}

In recent decades, changes in land use have led to increasing destruction and fragmentation of natural and seminatural habitats (Jennersten et al. 1992). As a consequence, many formerly more common plant species are now restricted to small and isolated populations. Even in intact habitat remnants, such as many nature reserves, such populations are expected to face a high risk of extinction because of environmental and demographic stochasticity (Boyce 1992) and because of Allee effects (Stephens \& Sutherland 1999), i.e. negative effects of small population size on plant fitness. Small plant populations may suffer from a disruption of interactions with their pollinators (Olesen \& Jain 1994; Bond 1995). Edge effects may be more important in small than in large populations (Gardner 1998). Moreover, genetic variation in small and isolated populations may be reduced compared with larger and more interconnected ones, which may decrease plant fitness and population viability (Ellstrand \& Elam 1993; Nunney \& Campbell 1993; Young et al. 1996).

In small and isolated populations, genetic drift can lead to the rapid fixation of alleles which decreases genetic variation and the evolutionary potential to adapt to environmental change (Falconer \& Mackay 1996). Furthermore, if the fixed alleles are deleterious mutations, population viability may directly be affected (Lynch et al. 1995). The degree of inbreeding in small and isolated populations may be increased due to generally reduced genetic variability, or to a changed mating structure, e.g. resulting from changed behaviour or availability of pollinators. If there is inbreeding depression this will lead to reduced plant fitness. Generally it is assumed that loss of genetic variation presents a stronger threat to formerly common species that have suffered recent reductions in their distribution than to naturally rare species (Huenneke 1991).

The discussion on phenotypic consequences of a loss of genetic variation has concentrated on average fitness, whereas phenotypic variation has received much less attention (Young et al. 1996). However, habitat fragmentation may affect not only mean fitness, but also phenotypic variation within and between environments, i.e. developmental instability (Siikamäki \& Lammi 1998) and phenotypic plasticity (Kéry et al. 2000). The avoidance 
of nonadaptive phenotypic variation, i.e. of developmental instability within individuals, may be hampered by reduced genetic variation (Young et al. 1996; Fowler \& Whitlock 1999). Because phenotypic stability of one trait may require a plastic response of other, e.g. physiological, traits, it may itself often represent adaptive plasticity. Because phenotypic plasticity is partly under genetic control it may be affected by a loss of genetic variation just as well as mean values of phenotypic characters. If, in addition, phenotypic plasticity is adaptive, a reduction due to reduced genetic variation or inbreeding may have negative effects on fitness. Possibly the best-known examples of adaptive plasticity in plants are their elongation of leaves and internodes in response to shade (Schmitt \& Wulff 1993; van Hinsberg \& van Tienderen 1997). To date, the effects of habitat fragmentation on adaptive phenotypic plasticity are unknown. Moreover, to date there are no studies that simultaneously consider effects of habitat fragmentation on plant performance, developmental stability, and phenotypic plasticity.

At present, the relative importance of genetic deterioration for the process of extinction is under debate (Caughley 1994; Schemske et al. 1994). Because many plant populations have become small and isolated only in recent decades, genetic deterioration is expected currently to affect only plants with short generation times, i.c. plants which are relying on frequent sexual reproduction (Fischer \& Matthies 1998a, b). However, the majority of plant species of the temperate flora has some means of clonal reproduction (Klimes et al. 1997), may therefore have very long generation times and as a consequence may suffer less in the short term. A positive correlation between population size and plant fitness in the field could also be due to differences in habitat quality, if high plant fitness in habitats of high quality leads to large population sizes. Therefore, a genetic basis for a positive relationship between population size and plant performance can only be demonstrated under controlled experimental conditions. The few experimental studies reported so far were common environment studies of plants with frequent seedling establishment, absent or little clonal growth and therefore short generation times (Menges 1991; Ouborg et al. 1991; Oostermeijer et al. 1994; Heschel \& Paige 1995; Fischer \& Matthies 1998a, b; Kéry et al. 2000).

To test whether genetic Allee effects may also occur in a plant with pronounced vegetative reproduction, we studied the stoloniferous herb Ranunculus reptans $\mathrm{L}$. This weak competitor occurs on periodically inundated shores of lakes where most interspecific competition is removed by flooding. Though seedling recruitment has been observed in this species it appears to be quite rare because summer inundation and unpredictable water level fluctuations do not allow seed maturation or seedling establish- ment in many years (Prati \& Peintinger 2000). This suggests a strong reliance on clonal growth and hence a long generation time for this species. In Europe, $R$. reptans has a subarctic-alpine distribution (Prati \& Peintinger 2000). As a consequence of the regulation of water levels of most lakes and of human impact on the shores of still unregulated lakes, the formerly more common habitat specialist has been restricted to small and isolated populations in the alpine region of Central Europe where it is now considered endangered (Landolt 1991; Korneck et al. 1996). There, $R$. reptans constitutes a good example of a clonal plant species whose geographical range and population sizes have declined because of human interference (Fischer et al. 2000). In a previous RAPD study, we found pronounced genetic differentiation among populations of $R$. reptans, suggesting high degrees of population isolation. Moreover, RAPD-variability in small populations was reduced compared with large populations of $R$. reptans, indicating a loss of genetic variation in small populations (Fischer et al. 2000).

Here, we study plants of $R$. reptans originating from 14 Lake-Constance populations of known size and of known RAPD-variability. To test the hypothesis that performance of plants from small populations is reduced because of genetic factors, we grew clonal progeny of plants of cach population in a controlled competition-free environment similar to natural conditions. This also allowed us to study phenotypic variation among replicates within genotypes as a measure of developmental instability. To test whether plasticity in leaf and internode lengths was reduced in small compared with large populations, we also grew plants in competition with the grass Agrostis stolonifera L. Our main question was how plant performance, phenotypic plasticity and developmental instability were associated with the size and RAPD-variability of the populations of $R$. reptans.

\section{MATERIALS AND METHODS}

\section{Study species}

Ranunculus reptans L. (crecping spearwort) is a stoloniferous species of the Ranunculaceae. Its potential distributional range comprises the temperate and boreal northern hemisphere (Hess et al. 1980). Because the weak competitor only penetrates very short distances into closed vegetation, which is typically dominated by the grass Agrostis stolonifera, it is restricted to sandy, gravel lake shores that are only sparsely populated by or entirely free of reed, woody species or graminoids (Lang 1967). At such lake shores, the species occurs in temporarily inundated areas. Whereas $R$. reptans is able to survive regular summer inundation for periods of $3-5$ months, 
competing grasses and sedges are suppressed by regular flooding. Because of the summer inundation, the typical length of the vegetation period for $R$. reptans is rather short and lasts only two to three months.

Ranunculus reptans reproduces vegetatively by secondarily rooting rosettes along horizontally growing stems. This enables a long life span of genets, which most likely may exceed decades (Markus Peintinger, Institut für Umweltwissenschaften, Universität Zürich, pers. comm.). Vegetative reproduction may lead to high rosette densities of $R$ reptans in the field. Because the number of rosettes in populations of $R$. reptans increases in years of short summer inundation and decreases in years of longer inundation, it can change strongly between years (Markus Peintinger, Institut für Umweltwissenschaften, Universität Zürich, pers. comm.). On average, plants of the selfincompatible $R$. reptans produce one insect-pollinated flower on every third rosette (Prati \& Peintinger 2000). Average infructescences contain 10-20 seeds. Because successful seedling establishment only occurs in years of short summer inundation (Prati \& Peintinger 2000), the realised average generation time is at least $3-5$ years, and is likely to be even longer (Markus Peintinger, Institut für Umweltwissenschaften, Universität Zürich, pers. comm.). The linear leaf blades of $R$. reptans narrow gradually into the petioles (Prati \& Peintinger 2000). Plants of $R$ reptans elongate their leaves and internodes in response to artificial shade (van Kleunen et al. 2000). However, because in the field shade is imposed by competing plants, leaf and internode elongation under competition may also be constrained by resource limitation.

\section{Study area and plant material}

At Lake Constance, the $R$. reptans habitats are approximately $10-\mathrm{m}$-wide bands of sandy gravel shore parallel to the winter water line. In spring 1995 and 1997, we sampled plants from 14 populations of $R$. reptans at Lake Constance in Germany, Austria and Switzerland. Distances between neighbouring populations ranged from 1.7 $\mathrm{km}$ to $32.6 \mathrm{~km}$, with a median of $4.0 \mathrm{~km}$.

To obtain a measure of population size, we estimated the area of every patch occupied by $R$. reptans and its percentage of ground cover in each population in November 1997, well after the inundation had ceased. We then estimated the area completely covered by $R$. reptans by summing the product of area and ground cover over all patches per population. Areas ranged over more than four orders of magnitude from 1 to $10^{4} \mathrm{~m}^{2}$. Because of our rather coarse estimates, we classified the populations in two equally sized groups: seven small populations $<100 \mathrm{~m}^{2}$, and seven large populations $>100 \mathrm{~m}^{2}$ (Fischer et al. 2000). Population densities and size of colonised areas may change among years depending on the duration of the summer inundation (Peintinger et al. 1997). However, because the water level is the same for all study populations at Lake Constance, it is not likely that the ranking of population sizes will change among years.

In each population, we selected one $20-\mathrm{m}$ stretch within the area colonized by $R$. reptans. In 10 populations, we sampled four to five rosettes along these stretches at distances of $5 \mathrm{~m}$ from each other. We then collected another four to five plants $5 \mathrm{~m}$ further inland. In this way, we collected eight to ten rosettes per population representing a $5 \times 20 \mathrm{~m}$ area. In four populations we sampled eight to ten rosettes closer than $5 \mathrm{~m}$ from each other because their total area was smaller than $5 \times 20 \mathrm{~m}$. Collected plants were propagated repeatedly and vegetative offspring were kept in a plant room at $25^{\circ} \mathrm{C}$ with $16 \mathrm{~h}$ of artificial light in $40 \times 70 \mathrm{~cm}$ trays filled with a $4: 1$ mixture of sand and gardening soil.

The plants sampled at Lake Constance were included in a study of RAPD (random amplified polymorphic DNA) variation among and within these 14 populations and another three populations sampled in a similar way in northern Italy (Fischer et al. 2000). Analysis of molecular variance (Excoffier et al. 1992) of the RAPD data revealed significant differentiation among populations $\left(F_{\mathrm{st}}=0.251, P<0.001 ;\right.$ Fischer et al. 2000), indicating isolation of populations because of limited gene flow. The estimation of population genetic parameters from the generally dominant RAPD data is based on the two crucial assumptions that null bands are homologous and that populations are in Hardy-Weinberg equilibrium (Lynch \& Milligan 1994; Ayres \& Ryan 1999). The selfincompatibility of $R$. reptans may prevent strong deviations from Hardy-Weinberg equilibrium. Moreover, the high levels of significance of differentiation among populations of $R$. reptans reported by Fischer et al. (2000) suggest that these results are rather robust to deviations from the assumptions.

Populations of $R$. reptans also differed significantly in their RAPD-diversity. Plant samples used for the determination of within-population RAPD diversity represented similar areas and similar sampling densities in small and large populations. Small populations had $24 \%$ less molecular variance (a measure of the largely selectively neutral RAPD-variation) than larger populations $(P<0.03$; Fischer et al. 2000), indicating genetic drift. If only the 14 Lake Constance populations were considered, the reduction was $22 \%$ and marginally significant $(P<0.09)$. Molecular variance of the 14 study populations ranged from 2.10 to 6.48 , i.c. these populations differed up to a factor 3 in their RAPD-diversity.

Habitats of the study populations were very similar. A map indicating the nutrient level in the littoral zone of 
Lake Constance is available for 1993 (Schmieder 1998). This map is based on records of the distribution of macrophyte species with different nutrient level requirements. Average nutrient level indices corresponded to moderate to considerable nutrient levels. Correlations of size and molecular variance of populations of $R$. reptans in 1995/97 with nutrient level indices per population were weak and not significant. Moreover, nutrient levels were not related to our measures of plant performance (see below).

\section{Greenhouse experiment}

To exclude clonal carry-over effects, we propagated all sampled plants at least five times prior to the experiment. To test whether performance of plants from small populations is reduced because of genetic factors, we grew clonal progeny of 102 plants from all 14 populations in a controlled competition-free environment. RAPD analysis confirmed that these 102 plants represented different genotypes (Fischer et al. 2000). We used replicates of 8 genotypes per population if there were enough replicates at the beginning of the experiment (from three populations we used replicates of 7 genotypes, from two others replicates of 6 genotypes and from another replicates of 5 genotypes). On 17 November 1997, we planted three rosettes of each genotype into $31 \times 44 \mathrm{~cm}$ trays filled with a 4:1 mixture of sand and gardening soil. The three rosettes per genotype were randomly assigned to planting positions in 39 trays.

To test whether plasticity in leaf and internode lengths was reduced in small compared with large populations, we grew three more replicates per genotype of $R$. reptans in competition with the taller Agrostis stolonifera in another set of 39 trays. Into these trays, we sowed seed of $A$. stolonifera, which germinated quickly and formed a dense matrix with about one plant per $\mathrm{cm}^{2}$ within two weeks. Agrostis stolonifera is a competitor of $R$. reptans in those parts of its natural habitats that are inundated for only relatively short periods of time, i.e. on the landward side of the $R$ reptans populations. We kept the trays in a plant room at $25{ }^{\circ} \mathrm{C}$ with $16 \mathrm{~h}$ of artificial light, and we reassigned them to new random positions weekly.

On 11-13 January 1998, after eight weeks of growth in the experiment, we recorded five variables for each plant. We counted the number of rosettes per plant, the number of rooted rosettes (as a measure of vegetative propagation) and the number of rosettes with flowers (as a measure of sexual reproduction). We did not harvest plants because they represented the first generation of a selection experiment. However, in another experiment, dry plant biomass (including the roots) was closely correlated with the number of rosettes per plant $(N=216, R=0.87, P<0.0001 ;$ Mark van Kleunen, unpublished data). The first three variables were used to measure plant fitness. To measure the amount of adaptive phenotypic plasticity in response to competition, we used two further variables, the combined length of the second and third stolon internodes, and the length of the longest leaf of the first daughter rosette. These measures are independent of the planted mother rosette which is important because we sowed the competing grass not until we planted the mother rosette.

\section{Data analysis}

We calculated within-genotype coefficients of variation among the three replicates grown in the competition-free environment for the five measured variables separately. We then obtained population means of these coefficients of variation, where higher values of this measure indicate higher developmental instability.

We quantified absolute plasticity per genotype in leaf and internode lengths as difference between the genotype means with and without competition. We quantified relative plasticity per genotype in these measures as absolute plasticity divided by genotype means over both environments. Despite the advantage of long leaves and internodes for capturing light, resource limitation may lead to shorter lengths of leaves and internodes under competition. In this case, plasticity in length of leaves and internodes may become negative. Because longer leaves and internodes are of advantage under competition, we considered a genotype with a smaller negative response in the length of leaves and internodes as more plastic than a genotype with a larger negative response.

In ANOVA models, we used sequential (i.e. 'Type I) sums of squares because of the hierarchical design with replicates nested within genotypes, genotypes nested within populations and populations nested within population-size classes. Accordingly, we tested effects of RAPDvariability (molecular variance) and population size against variation among populations, variation among populations against variation among genotypes and variation among genotypes against residual variation among replicates. With one exception (the number of rooted rosettes), the levels of significance of population size and molecular variance were independent of their sequence in the model, and they remained the same if only one of these two factors was included. In Table 1 we present the model where molecular variance is fitted first, and in the text we report the deviations between different models for the number of rooted nodes. Using MANOVA, we tested the effect of molecular variance and population size on population means of within-genotype coefficients of variation for the five measured traits. Levels of significance of the MANOVA remained the same if only 
Table 1 ANOVA for the relationship between population characteristics of Ranunculus reptans and measures of plant performance in a competition-free common environment. Plants in the experiment represented 102 genotypes from 14 populations. Effects of molecular variance (RAPD variability, see Methods) and population size were tested against variation among populations, and variation among populations was tested against variation among genotypes. The number of residual degrees of freedom was 210 for the analysis of the number of all rosettes.

\begin{tabular}{|c|c|c|c|c|c|c|c|}
\hline \multirow[b]{3}{*}{ Source of variation } & \multirow[b]{3}{*}{ d.f. } & \multicolumn{6}{|c|}{ Number of } \\
\hline & & \multicolumn{2}{|c|}{ Flowering rosettes } & \multicolumn{2}{|c|}{ Rooting rosettes } & \multicolumn{2}{|c|}{ All rosettes } \\
\hline & & MS & $\mathrm{F}$ & MS & $\mathrm{F}$ & MS & $\mathrm{F}$ \\
\hline Molecular variance & 1 & 7.5 & 0.205 & 50.6 & $5.386 *$ & 113.3 & 0.544 \\
\hline Population size & 1 & 322.3 & $8.777^{*}$ & 15.9 & 1.688 & 1140.7 & $5.477 *$ \\
\hline Population & 11 & 36.7 & 0.754 & 9.4 & 0.910 & 208.3 & 1.157 \\
\hline Genotype (Population) & 88 & 48.7 & $1.750 * * *$ & 10.3 & $1.567 * *$ & 179.90 & $1.651 * *$ \\
\hline Residual & 208 & 27.8 & & 6.6 & & 109.0 & \\
\hline
\end{tabular}

$* P<0.05 ; * * P<0.01 ; * * * P<0.001$.

one of the two factors was included. For all statistical analyses, we used the software package JMP (release 3.1, SAS Institute, Cary, NC, USA).

\section{RESULTS}

\section{Plant performance}

After eight weeks of growth in the competition-free environment, there was significant variation in the numbers of rosettes among genotypes within populations ('Table 1). Plants from large field populations performed better than plants from small populations. Plants, on average, had 13.5 rosettes, of which 4.0 were rooted, and 5.6 had a flower. Plants originating from large populations had $28.7 \%$ more flowering rosettes than plants from small populations $\left(F_{1,11}=8.78\right.$; $P<0.02$; Fig. 1), $17.6 \%$ more rooted rosettes $(n$. s. $)$, and $22.7 \%$ more rosettes in total $\left(F_{1,11}=5.48 ; P<0.04\right)$.

Similarly, plants from populations with greater molecular variance had more rooted rosettes than plants from populations with less molecular variance. The latter effect was significant when we fitted molecular variance before population size $\left(F_{1,11}=5.39 ; P<0.05\right.$; Fig. 1$)$, and when we omitted population size from the $\operatorname{model}\left(F_{1,12}=5.10 ; P\right.$ $<0.05$ ). If we fitted population size before molecular variance, the effect of molecular variance was not significant. However, in this case, and when we omitted molecular variance from the model, the positive effect of larger population size on the number of rooted rosettes per plant was marginally significant $\left(F_{1,11}=4.74 ; P<0.06\right.$, and $F_{1,12}=4.26 ; P<0.07$, respectively).

\section{Developmental stability}

Mean coefficients of variation within genotypes were not significantly lower in larger populations than in smaller

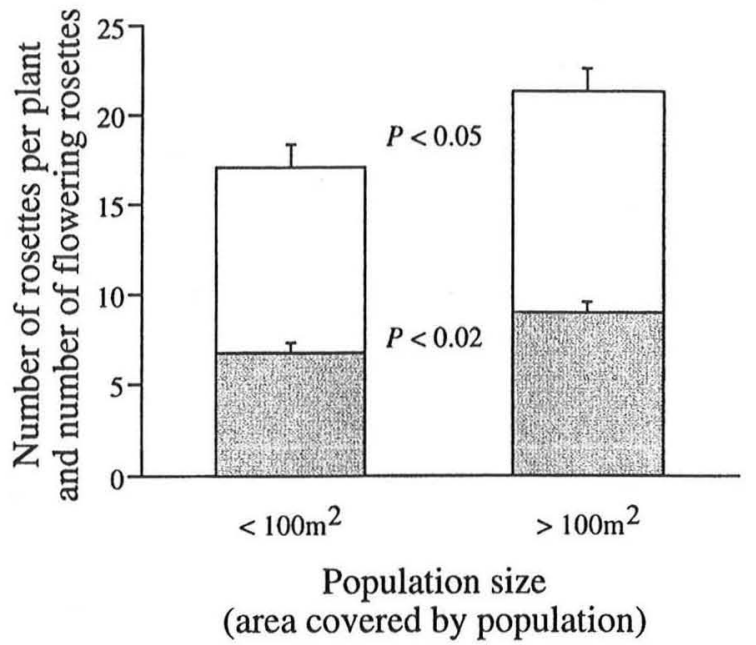

Figure 1 The relationship between the common-environment performance of plants derived from 14 populations of Ranunculus reptans and population size (measured as area completely covered by the population in autumn 1997). Measures of performance are the number of rosettes per plant (total columns) and the number of flowering rosettes per plant (shaded part). Significance levels given in the graphs were obtained with ANOVA tests.

populations, with the only exception of a very weak positive relationship for the number of rooting rosettes. Within-genotype variation in all five measured traits was negatively related to molecular variance of the populations (MANOva; Wilk's $\lambda=0.954$; exact $F_{1,11}=10.0 ; P<$ 0.01 ; Fig. 2). This indicates that genotypes from populations with higher RAPD-variability were developmentally more stable than genotypes from populations with lower RAPD-variability. 


\section{Phenotypic plasticity}

After eight wecks in the competition-free environment, the average combined length of the second and third stolon internode was $51.9 \mathrm{~mm}$, and the average length of the longest leaf of the first daughter rosette was $19.3 \mathrm{~mm}$. After eight weeks under competition, planted genotypes

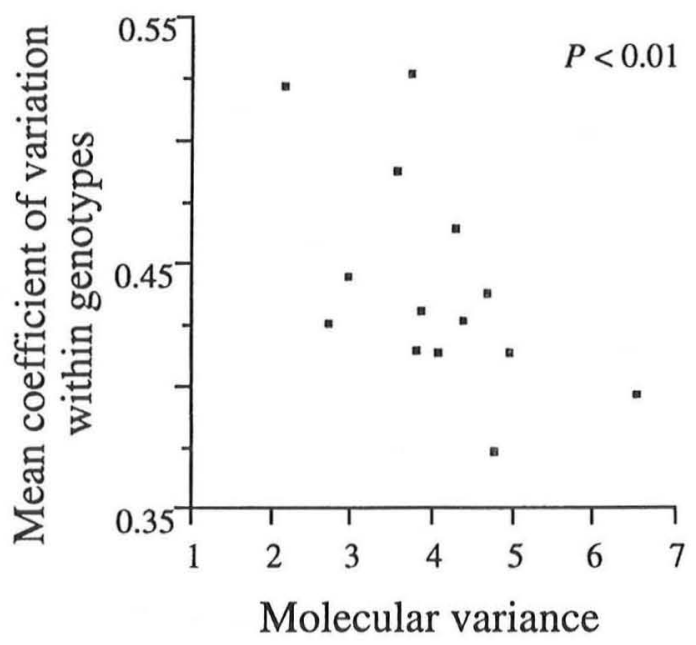

Figure 2 The relationship between the mean within-genotype coefficient of variation for five plant traits in a common environment (as a measure of developmental instability) and the molecular variance (as a measure of RAPD variability) of 14 populations of origin of Ranunculus reptans. This graph illustrates a negative correlation which is significant at the $1 \%$ level in a MANOVA test. had shorter internodes (combined length of second and third stolon internode $3.6 \mathrm{~mm}$ shorter) and leaves (longest leaf of first daughter rosette $5.6 \mathrm{~mm}$ shorter) than without competition. Under competition, those genotypes with long leaves of the first daughter rosette had more rosettes than genotypes with short leaves ( $N=102$ genotypes, $R=0.24, P<0.02$ ), while this relationship was not significant in the competition-free environment $(R=0.11$, $P>0.29)$. This suggests that the production of longer leaves under competition is indeed adaptive in $R$. reptans. In response to competition, relative plasticity in internode length was $-9.8 \%$ and relative plasticity in leaf length was $-42 \%$. The relative reduction in leaf length was less pronounced for plants from large than from small populations $\left(F_{1,11}=6.96 ; P<0.03\right.$; Table 2 ; Fig. 3$)$, suggesting a higher potential of plants from large populations to overcome the negative influence of competition. This higher resistance of plants from larger populations to change of a nonadaptive kind indicates higher adaptive plasticity.

\section{DISCUSSION}

\section{Plant performance}

We observed reduced performance of plants from small populations of $R$. reptans in the common garden (Fig. 1). If environmental variables were correlated with population size, they could, through maternal carry-over effects, be responsible for the observed pattern in the common garden (Oostermeijer et al. 1994). However, this is

Table 2 ANOVA for the relationship between population characteristics of Ranunculus reptans and plasticity of genotypes in response to competition. Absolute plasticity denotes the difference between the trait in the competition-free and the competitive environment. Relative plasticity denotes absolute plasticity divided by the trait mean over both environments. Plants in the experiment represented 102 genotypes from 14 populations. Effects of molecular variance (RAPD variability, see Methods) and population size were tested against variation among populations, and variation among populations was tested against variation among genotypes.

\begin{tabular}{|c|c|c|c|c|c|c|}
\hline \multirow[b]{2}{*}{ Source of variation } & \multirow[b]{2}{*}{ d.f. } & \multicolumn{2}{|c|}{$\begin{array}{l}\text { Combined length of second } \\
\text { and third stolon internodes }\end{array}$} & \multirow[b]{2}{*}{ d.f. } & \multicolumn{2}{|c|}{$\begin{array}{l}\text { Length of longest leaf of } \\
\text { first daughter rosette }\end{array}$} \\
\hline & & MS & $\mathrm{F}$ & & MS & $\mathrm{F}$ \\
\hline \multicolumn{7}{|l|}{ Absolute plasticity } \\
\hline Molecular variance & 1 & 326.2 & 1.249 & 1 & 29.5 & 0.646 \\
\hline Population size & 1 & 15.4 & 0.059 & 1 & 64.0 & 1.404 \\
\hline Population & 11 & 261.1 & $1.828+$ & 11 & 45.6 & 0.642 \\
\hline Genotype (Population) & 84 & 142.8 & & 88 & 71.1 & \\
\hline \multicolumn{7}{|l|}{ Relative plasticity } \\
\hline Molecular variance & 1 & 0.090 & 0.907 & 1 & 0.011 & 0.066 \\
\hline Population size & 1 & 0.002 & 0.021 & 1 & 1.121 & $6.963 *$ \\
\hline Population & 11 & 0.099 & $1.793+$ & 11 & 0.161 & 0.345 \\
\hline Genotype (Population) & 84 & 0.055 & & 88 & 0.467 & \\
\hline
\end{tabular}

$+P<0.10 ; * P<0.05$. 


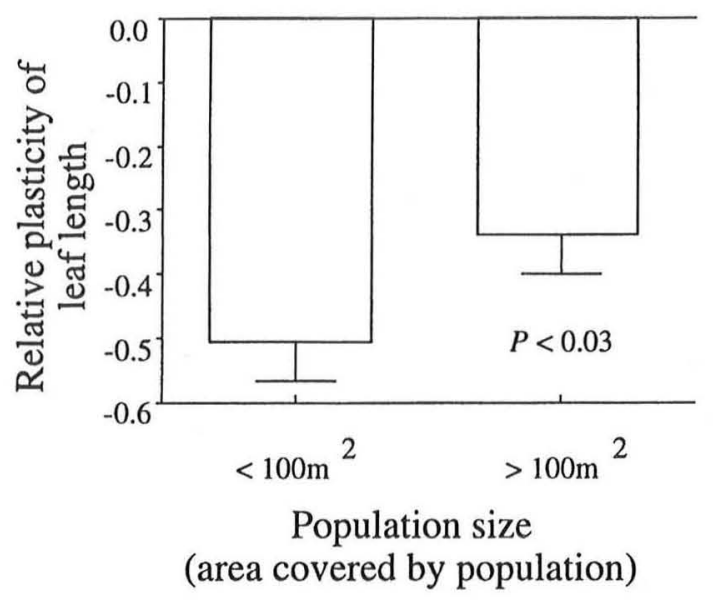

Figure 3 The relationship between phenotypic plasticity of plants derived from 14 populations of Ranunculus reptans and the size of these populations (measured as area completely covered by the population in autumn 1997). To assess phenotypic plasticity, vegetative replicates of all plants were grown with and without competition with the grass Agrostis stolonifera. Relative plasticity in the length of the longest leaf of the first daughter rosette is the difference between leaf lengths measured with competition and without competition divided by mean leaf length over both environments. The relationship shown is significant at the $3 \%$ level in an ANOVA test.

unlikely in our study. While maternal environmental conditions influence offspring performance mostly during the early stages of development (Roach \& Wulff 1987), we propagated rosettes of $R$ reptans repeatedly prior to our experiment in a common environment. Moreover, amongpopulation variation in recent macrophyte-based nutrient indices was independent of population size (see methods section). Hence, we conclude that the reduced performance of plants from smaller populations of $R$. reptans in the common environment is not a carry-over effect, indicating variation in habitat quality, but a genetic effect.

Both population size and measures of plant performance were independent of per-population nutrient indices, which indicate the environmental factor that is probably most variable among the otherwise very similar habitats of $R$. reptans. Therefore, it is highly unlikely that the sand-soil mixture used for our experiment is accidentally more similar to natural substrate in large populations than to that in small ones. This suggests that the genetic effect is not related to local adaptation. A positive relationship between plant peformance and population size could also have come about after severe bottlenecks in all populations, which may have left only few genotypes in all populations at a certain time. If these genotypes by chance were fitter in some populations than in others, the populations with well performing genotypes would have grown larger than the populations with the poorer performing genotypes, resulting in the observed pattern of better performing genotypes in larger populations. However, this explanation is unlikely in our case, because it does not explain the higher genetic diversity of larger compared with smaller populations. Therefore, we conclude that the observed higher performance of plants from larger populations was due to population size itself, i.e. that we observed a genetically based Allec effect (Stephens et al. 1999).

Genetic drift as well as occasional bottlenecks, which may be more likely to occur in nature than steady genetic drift, lead to a reduction in genetic variation in isolated populations (Frankham 1996; Young et al. 1996). The degree of isolation of populations of $R$. reptans even increased in recent decades (Thomas et al. 1986). Because the high number of rosettes in populations of $R$. reptans is mainly due to vegetative reproduction (Prati \& Peintinger 2000 ), it exceeds by far the number of different genotypes per population and therefore effective population size. Because effective population size determines the degree of genetic drift, this suggests that genetic drift is an important force in populations of $R$. reptans. The ratio between effective population size and the number of rosettes in a population could further be reduced due to variation in neighbourhood sizes and fluctuations in the number of genotypes in a population (Frankham 1995). Correspondingly, the ratio between effective population size and census population size ranged from 0.002 to 0.676 in a review of 38 plant species (Frankham 1995). Pronounced between-year fluctuations in the duration of the summer inundation of Lake Constance causes fluctuations in the number of rosettes per population of $R$ reptans (Prati \& Peintinger 2000). Very long durations of the summer inundations, such as the unusual recent period (1997-2000) where large parts of our study populations were flooded for more than two years, may cause bottlenecks. Moreover, the high degree of eutrophication of Lake Constance in the 1970s, which led to the frequent deposition of large masses of algae on the lake shores populated by $R$. reptans, may also have caused bottlenecks (Thomas et al. 1986). RAPDvariability was reduced in smaller compared with larger populations of $R$. reptans, which suggests that genetic drift and bottlenecks have reduced genetic variation more strongly in small than in large populations (Fischer et al. 2000). Reduced genetic variation will lead to increased inbreeding coefficients because of biparental inbreeding, even for self-incompatible species, such as $R$. reptans (Ellstrand \& Elam 1993).

Inbreeding depression can be expressed at all stages of the life cycle. Very deleterious mutations are assumed to be expressed earlier in the life-cycle while mildly detrimental mutations may also be acting late in life. 
While more severe mutations are more likely to be purged by inbreeding, mildly detrimental late-acting mutations can hardly be purged (Husband \& Schemske 1996). Moreover, empirical data suggest that purging of inbreeding depression is not a consistent force in evolution (Byers \& Waller 1999). We studied plant performance at the late stage after rosette establishment. We conclude that the performance reductions we observed in plants from smaller populations of $R$. reptans may well have resulted from increased levels of inbreeding in smaller populations leading to increased expression of inbreeding depression.

While the prediction of reduced plant fitness in small populations of plants is well founded in genetic theory, there are very few empirical studies which have related measures of fitness to population size in plants (Young et al. 1996). Moreover, the results of these studies have not always indicated negative effects of small population size on plant performance, and if they did, this was not always interpreted as an effect of inbreeding depression (Lamont $e t$ al. 1993; Groom 1998). Seed mass, germination rate and response to clipping in the monocarpic perennial Ipomopsis aggregata were positively related to population size and interpreted as effects of increased inbreeding in smaller populations (Heschel \& Paige 1995). Reduced germination rates in small fragmented populations of the perennial Silena regia were also explained by inbreeding depression (Menges 1991). Survival and reproduction of plants of Gentianella germanica in the common garden were positively related to size and RAPD variability of populations, which was attributed to genetic erosion (Fischer \& Matthies 1998a, b). No clear correlations between population size and measures of plant fitness in a common environment were found in another rare perennial plant, Salvia pratensis (Ouborg \& van Treuren 1995).

\section{Developmental instability and phenotypic plasticity}

There have been very few studies that have related phenotypic variation to population size in plants. In Salvia pratensis and Scabiosa columbaria, levels of phenotypic variation in growth traits were positively related to population size (Ouborg et al. 1991), while in Gentiana pneumonanthe smaller populations appeared somewhat more variable in growth traits and in phenotypic traits than larger populations (Oostermeijer et al. 1994). However, it is not clear whether these patterns in populations of different size reflect variation within or among genotypes.

Phenotypic variation within genotypes from genetically more diverse populations of $R$. reptans was smaller than within genotypes from less diverse populations (Fig. 2). This indicates that genetically more diverse populations consist of genotypes with higher developmental stability. Higher developmental stability for larger or genetically more diverse populations was reported for the plants Lychnis viscaria (Siikamäki \& Lammi 1998), Gentiana pneumonanthe (Oostermeijer et al. 1995), for a lizard (Sarre \& Dearn 1991) and a gecko (Sarre 1996). However, the opposite pattern of decreased developmental stability with increasing population size was found in Phlox pilosa (Heard et al. 1999). In our study populations, lower within-genotype coefficients of variation were associated with a higher average number of rooting rosettes. This corresponds well with the pattern that more developmentally stable individuals generally have faster growth, higher fecundity and higher survival than less stable ones (Møller 1997).

A reduction in adaptive plasticity because of reduced genetic variation in smaller populations may be associated with reduced fitness in spatially or temporally heterogeneous environments. Plasticity in plant growth in response to fertilisation was higher for plants grown from seeds collected in larger populations of Primula veris than from smaller populations (Kéry et al. 2000). However, because plants from larger populations of $P$. veris had also grown larger in a common environment, relative plasticity was similar for plants from larger and from smaller populations. Moreover, it is not clear whether this response reflects adaptive or passive plasticity. In our study, plants from larger populations of $R$. reptans showed a lower relative reduction in leaf length than plants from smaller populations (Table 2; Fig. 3 ), suggesting that adaptive plasticity was limited in plants from smaller populations.

\section{CONCLUSIONS}

We report positive relationships between population size and fitness, population size and adaptive phenotypic plasticity, and between per-population molecular variance and developmental stability in the clonal plant $R$. reptans. We conclude that genetic Allee effects after habitat fragmentation may threaten the persistence even of clonal plants with predominantly vegetative reproduction and therefore long generation times. This suggests that genetic effects of habitat fragmentation are more severe and more common than previously acknowledged. This is of particular importance for conservation, because many nature reserves are small and isolated. Our study underlines the necessity to consider population genetics in conservation biology.

\section{ACKNOWLEDGEMENTS}

We thank Rahel Schmid, Veronika Stöckli, Franz Fritsche, Thomas Pfluger and Alexander Tchouboukov 
for help with the measurements, Markus Peintinger and Daniel Prati for information on the natural history of the species and on its situation at Lake Constance, Bitty Roy and Jacqui Shykoff for constructive comments and the Swiss National Science Foundation for financial support (Grant 31-49728.96).

\section{REFERENCES}

Ayres, D.R. \& Ryan, F.J. (1999). Genetic diversity and structure of the narrow endemic Wyethia reticulata and its congener $W$. bolanderi (Asteraceae) using RAPD and allozyme techniques. Am. J. Botany, 86, 344-353.

Bond, W.J. (1995). Assessing the risk of local extinction due to pollinator and disperser failure. In: Extinction Rates (ed. Lawton, J.H. \& May, R.M.) Oxford University Press, Oxford, UK, pp. 131-146.

Boyce, M.S. (1992) Population viability analysis. Annu. Rev. Ecol. Syst, 23, 481-506.

Byers, D.L. \& Waller, D.M. (1999). Do plant populations purge their genetic load? Effects of population size and mating history on inbreeding depression. Annu. Rev. Ecol. Syst, 30, 479-513.

Caughley, G. (1994). Directions in conservation biology. J. Anim Ecology, 63, 215-244.

Ellstrand, N.C. \& Elam, D.R. (1993). Population genetic consequences of small population size: implications for plant conservation. Annu. Rev. Ecol. Syst, 24, 217-243.

Excoffier, L., Smouse, P.E. \& Quattro, J.M. (1992). Analysis of molecular variance inferred from metric distances among DNA haplotypes: application to human mitochondrial DNA restriction data. Genetics, 131, 479-491.

Falconer, D.S. \& Mackay, T.F.C. (1996). Introduction to Quantitative Genetics. Longman. Harlow, Essex, UK.

Fischer, M. \& Matthies, D. (1998a). Effects of population size on performance in the rare plant Gentianella germanica. J. Ecol., 86, 195-204.

Fischer, M. \& Matthies, D. (1998b). RAPD variation in relation to population size and plant performance in the rare. Gentianella germanica. Am. J. Botany, 85, 811-819.

Fischer, M., Husi, R., Prati, D., Peintinger, M., van Kleunen, M. \& Schmid, B. (2000). RAPD variation among and within small and large populations of the rare clonal plant Ranunculus reptans (Ranunculaceae). Am. J. Botany, 87, 1128-1137.

Fowler, K. \& Whitlock, M.C. (1999). The distribution of phenotypic variance with inbreeding. Evolution, 53, 1143-1156.

Frankham, R. (1995). Effective population size/adult population size ratios in wildlife: a review. Genet Res., 66, 95-107.

Frankham, R. (1996). Relationship of genetic variation to population size in wildlife. Conservation Biol., 66, 1500-1508.

Gardner, J.L. (1998). Experimental evidence for edge-related predation in a fragmented agricultural landscape. Aust. J. Ecology, 23, 311-321

Groom, M.J. (1998). Allee effects limit population viability of an annual plant. The Am. Naturalist, 151, 487-496.

Heard, S.B., Campbell, M.A., Bonine, M.L. \& Hendrix, S.D. (1999). Developmental instability in fragmented populations of prairic phlox: a cautionary tale. Conservation Biol., 13, 274281.
Heschel, M.S. \& Paige, K.N. (1995). Inbreeding depression, environmental stress, and population size variation in scarlet gilia (Ipomopsis aggregata). Conservation Biol., 9, 126-133.

Hess, H.E., Landolt, E. \& Hirzel, R. (1980). Flora der Schweiz, Vol. 2. Birkhäuser, Basel, Switzerland.

van Hinsberg, A. \& van Tienderen, P. (1997). Variation in growth form in relation to spectral light quality (red/far-red ratio) in Plantago lanceolata L. in sun and shade populations. Oecologia, 111, 452-459.

Huenneke, L.F. (1991). Ecological implications of genetic variation in plant populations. Genetics and Conservation of Rare Plants (eds Falk, D.A. \& Holsinger, K.E.). Oxford University Press. New York, NY, USA, pp. 31-44.

Husband, B.C. \& Schemske, D.IW. (1996). Evolution of the magnitude and timing of inbreeding depression in plants. Evolution, 50, 54-70.

Jennersten, O., Loman, J., Møller, A.P., Robertson, J. \& Widén, B. (1992). Conservation biology in agricultural habitat islands. In: Conservation Biology by Ecological Principles (ed. Hansson, L.) Elsevier, London, UK, pp. 396-425.

Kéry, M., Matthies, D. \& Spillmann, H.H. (2000). Reduced fecundity and offspring performance in small populations of the declining grassland plants Primula veris and Gentiana lutea. J. Ecol., 88, 17-30.

van Kleunen, M., Fischer, M. \& Schmid, B. (2000). Clonal integration in Ranunculus reptans. by-product or adaptation? J. Evol Biology, 13, 237-248.

Klimes, L., Klimesová, J., Hendriks, R. \& van Groenendael, J. (1997). Clonal plant architecture: a comparative analysis of form and function. In: The Ecology and Evolution of Clonal Plants (eds. de Kroon, H. \& van Groenendael, J.) Backhuys, Leiden, The Netherlands, pp. 1-29.

Korneck, D., Schnittler, M. \& Vollmer, I. (1996). Rote Liste der Farn-und Blütenpflanzen (Pteridophyta et Spcrmatophyta) Deutschlands. Schriftenreihe Vegetationskunde, 28, 21-187.

Lamont, B.B., Klinkhamer, P.G.L. \& Witkowski, E.T.F. (1993). Population fragmentation may reduce fertility to zero in Banksia goodii - a demonstration of the Allee effect. Oecologia, 94, 446-450.

Landolt, E. (1991). Gefährdung der Farn-und Blütenpflanzen in der Schweiz. Bundesamt für Umwelt, Wald und Landschaft (BUWAL), Bern, Switzerland.

Lang, G. (1967). Die Ufervegetation des westlichen Bodensees. Arch. Hydrobiologie, (Suppl. 32), 437-574.

Lynch, M., Conery, J. \& Bürger, R. (1995). Mutation accumulation and the extinction of small populations. Am. Naturalist, 146, 489-518.

Lynch, M. \& Milligan, B.G. (1994). Analysis of population genetic structure with RAPD markers. Mol Ecol., 3, 91-99.

Menges, E.S. (1991). Seed germination percentage increases with population size in a fragmented prairie species. Conservation Biol., 5, 158-164.

Moller, A.P. (1997). Developmental stability and fitness: a review. Am. Naturalist, 149, 916-932.

Nunney, L. \& Campbell, K.A. (1993). Assessing minimum viable population size: demography meets population genetics. Trends Ecol. Evolution, 18, 234-239.

Olesen, J.M. \& Jain, S.K. (1994). Fragmented plant populations and their lost interactions. In: Conservation genetics (eds. Loeschcke, V., Tomiuk, J. \& Jain, S.K.) Birkhäuser, Basel, Switzerland, pp. 417-426. 
Oostermeijer, J.G.B., van Eijck, M.W. \& den Nijs, J.C.M. (1994). Offspring fitness in relation to population size and genetic variation in the rare perennial plant species Gentiana pneumonanthe (Gentianaceae). Oecologia, 97, 289-296.

Oostermeijer, J.G.B., van Eijck, M.W., van Leeuwen, N.C. \& den Nijs, J.C.M. (1995). Analysis of the relationship between allozyme heterozygosity and fitness in the rare Gentiana pneumonanthe L. J. Evol Biology, 8, 739-757.

Ouborg, N.J. \& van Treuren, R. (1995). Variation in fitnessrelated characters among small and large populations of Salvia pratensis. J. Ecol., 83, 369-380.

Ouborg, N.J., van 'Treuren, R. \& van Damme, J.M.M. (1991). Morphological variation and fitness components in populations of varying size of Salvia pratensis L. \& Scabiosa columbaria L. Oecologia, 86, 359-367.

Peintinger, M., Strang, I., Dienst, M. \& Meyer, C. (1997). Veränderung der gefährdeten Starndschmielengesellschaft am Bodensee zwischen 1989 und 1994. Z Ökologie Naturschutz, 6, 75-81.

Prati, D. \& Peintinger, M. (2000). Biological flora of central europe: Ranunculus reptans L. Flora, 195, 135-145.

Roach, D.A. \& Wulff, R.D. (1987). Maternal effects in plants. Annu. Rev. Ecol. Syst, 18, 209-235.

Sarre, S. (1996). Habitat fragmentation promotes fluctuating asymmetry but not morphological divergence in two geckos. Researches Popul. Biol., 38, 57-64.

Sarre, S. \& Dearn, J.M. (1991). Morphological variation and fluctuating asymmetry among insular populations of the sleepy lizard, Trachydosaurus rugosus Gray (Squamata, Scincidae). Aust. J. Zoology, 39, 91-104.

Schemske, D.W., Husband, B.C., Ruckelshaus, M.H., Goodwillie, C., Parker, I.M. \& Bishop, J.G. (1994). Evaluating approaches to the conservation of rare and endangered plants. Ecology, 75, 584-606.

Schmieder, K. (1998). Submerse Makrophyten der Litoralzone des Bodensees 1993 im Vergleich mit 1978 und 1967.
Berichte internationale Gewässerschutzkommision Den Bodensee, 46, 1-169.

Schmitt, J. \& Wulff, R.D. (1993). Light spectral quality, phytochrome and plant competition. Trends Ecol. Evolution, 8, 47-51

Siikamäki, P. \& Lammi, A. (1998). Fluctuating asymmetry in central and marginal populations of Lychnis viscaria in relation to genetic and environmental factors. Evolution, 52, 1285-1292.

Stephens, P.A. \& Sutherland, W.J. (1999). Consequences of the Allee effect for behaviour, ecology and conservation. Trends Ecol. Evolution, 14, 401-405.

Stephens, P.A., Sutherland, W.J. \& Freckleton, R.P. (1999). What is the Allee-effect? Oikos, 87, 185-190.

Thomas, P., Dienst, M., Peintinger, M. \& Buchwald. R. (1986). Die Strandschmielengesellschaft des Bodensees (Deschampsietum rhenanae und Littorello-Eleocharitetum acicularis). Verbreitung, Ökologie, Gefährdung und Schutzmassnahmen. Veröffentlichungen Naturschutz Landespflege Baden-Württemberg, $62,325-346$

Young, A., Boyle, T. \& Brown, T. (1996). The population genetic consequences of habitat fragmentation for plants. Trends Ecol. Evolution, 11, 413-418.

\section{BIOSKETCH}

Markus Fischer is research associate. His main research interests are conservation biology, the population biology (i.e. both ecology and genetics) of rare, of clonal and of invasive plants, and life-history evolution. 